\title{
The Social Value of Xinjiang Complex
}

\author{
Wenliang Li \& Yuzhen Ding \\ College of humanities, Yili Normal University, Yining 835000, China
}

\begin{abstract}
For centuries, Xinjiang complex which is active in public life has strong vitality. It can both educate and entertain, simultaneously is inclusive and inheriting the culture. It is less elegant but unpretentious, making it highly unified in the ideological and artistic aspects. Its value is far beyond the arts. So, this paper intends to do preliminary study on the social value of Xinjiang complex.
\end{abstract}

KEYWORD: Xinjiang; complex; The Social Value

\section{INTRODUCTION}

Xinjiang complex is a unique form of folk speaking class which is widely popular in Xinjiang region. It narrates stories and expresses emotions in Chinese Xinjiang dialect using language arts and rhetorical devices such as a rhyme, metaphor, pun and hyperbole, coupled with humor and playful dialect, rhythmic folk proverbs, slang, jingle, etc. It is loved by the masses owing to its understandable contents and profound implication. Saying miscellaneous dialect is also called "slipping miscellaneous," "putting down the mouth" and "saying paragraphs". Originated in the nineteenth century, Xinjiang complex is active in the social life of the people in Xinjiang, especially popular in the northern region for hundreds of years. Despite enormous changes in economy and society in Xinjiang for centuries, Xinjiang complex is always popular on many cases in the everyday life of masses in different ways. It breakthroughs the limits of time and space, becoming more popular, having more people and being more closely in touch with the masses in everyday life. In April 2007, Xinjiang complex was included in the first batch of intangible cultural heritage of Xinjiang Uygur Autonomous Region as a result of its unique artistic charm, deep and broad mass bases and irreplaceable social values. Thence, this folk grassroots literature gained the world's concern and attention and its deserved place in Xinjiang Cultural Heritage List.

For centuries, Xinjiang complex which is active in public life has strong vitality. It can both educate and entertain, simultaneously is inclusive and inheriting the culture. It is less elegant but unpretentious, making it highly unified in the ideological and artistic aspects. It has a high pleasant and educational function in society. There is no substitute for its role of cultural heritage and building a harmonious society. Its value is far beyond the arts. So, this paper intends to do preliminary study on the social value of Xinjiang complex.

\section{FUNCTION OF ABSURD AND HUMOR ENTERTAINMENT}

"If all the family property is left with only two nangs (a kind of crusty pancake), one is used to eat, the other can be used as a tambourine to compose music for dance." This proverb, though some to exaggerate, is enough to see Xinjiang people's optimism. The inherent impression of Xinjiang is usually distant, desolate and barren. This land, however, is never lack of laughter. There is world-renowned famous Uighur comedian Avanti. The place is also popular in Xinjiang miscellaneous dialect using Chinese Xinjiang words. Xinjiang miscellaneous dialect and Avanti joke both circulate orally in people of all nationalities in Xinjiang and spread widely in laughter.

From the development of Xinjiang miscellaneous dialect for centuries, we know that the basic reason why it can develop is its cheerfulness. Its primary purpose was to amuse people in an absurd and humor way, then lead to other. At different times, Xinjiang miscellaneous dialect kept pleasing people's lives in different ways, always following the mainstream of communication and culture.

While the appearance of Xinjiang miscellaneous dialect in the late Ming and early Qing dynasty, it is 
mainly active in traditional festivities, temple fairs, wedding or mourning banquets and other occasions, especially popular in temple fairs. Xinjiang BarryKun kazak autonomous county, where Xinjiang miscellaneous dialect was widely spread, was regarded as "Xinjiang temple crown" in the late Ming and early Qing dynasty. Where there was temple, there was temple fair. In the old times, there were 11 temples with theater in BarryKun such as Laojun Temple, Guanyue Temple, Shanxi Temple, Niangniang Temple, Mawang Temple, Dizang Temple, Sanguan Temple, Guandi Temple, Longwang Temple, Nanshan Temple. Temples without fixed theater would perform on a contemporary stage ${ }^{[1]}$. From the beginning of lunar January, there are temples acting in an opera to express gratitude toward god, sometimes even several times a month. Large-scale temple festival would act for three days, attracting urban and rural residents to swarm there. The representative temple festivals were on 15 lunar January, beginning of spring, pure brightness, 19 lunar April, 13 lunar May, 16 lunar May, 25 lunar May, 6 lunar June, 7 lunar July, 9 lunar September and October First. At the beginning of acting on the temple, the clown would perform Xinjiang miscellaneous dialect as introductory remarks to amuse the masses and gather popularity. Besides, in order to attract customers and sell merchandise, some peddlers selling candy or dry fruit often made up a set of miscellaneous dialect speech in a gambling and 'Shaking' form. Seeing from the content and performance form of early works such as Dogskin Plaster, Good Weather Good Year (prevalent in the year about 1931-1946), their purpose was to please the audience and attract attention, which was so-called 'treading the stage'. Acting miscellaneous dialect was a 'little perform' with cheerfulness before the formal temple fair.

During the second stage of Xinjiang miscellaneous dialect acting from 1949 to the end of 20 century, people's living standards improved. Since the 3rd Plenary Session of 11th Party Central Committee when the status of Xinjiang miscellaneous dialect actors enhanced, they heartily eulogized new society and new life. Consequently, Xinjiang miscellaneous dialect got on the big and stately stage. Xinjiang miscellaneous dialect work Biography of Wang San created and performed by Wang Jinhui, for example, winned the 'excellent creation award of art performance' in Changji Hui Autonomous Prefecture. Xinjiang miscellaneous dialect work Plant Melon the First Year, Lose Account the Second Year by Ma Deming, using people and things around as the material, is full of jokes by conscious creation and performance. This also marks Xinjiang miscellaneous dialect formally entered people's cultural and recreational life as folk art in the new era. Miscellaneous dialect actor such as Ma Yaohui and Bai Fajian in HaMi, Su Ze and
Yao Pianchuan in BarryKun were always active in the development and spread of Xinjiang miscellaneous dialect according to their own life experiences and understanding on local culture life. Although not performing on stage, they brought joy to the masses in the rural areas where information media was underdeveloped. That was why they were also at the local prestigious.

Since twenty-first century, with the rapid development of economic society and the advent of information and network era, Xinjiang miscellaneous dialect came into people's life in new ways such as tapes, CD, network, etc. The main representative was $\mathrm{CD}$ of three sets Xinjiang folk miscellaneous dialect by the famous miscellaneous dialect actor Zhao Guozhu, which included 40 works such as Foreign Friends Praise Xinjiang, Young People should be on the Right Road, etc. Those works became extremely popular once issued, causing miscellaneous dialect fever in Xinjiang. There were full of laughter in the streets, restaurants, teahouses, buses, taxies, audio shops, etc, making more people understand and love Xinjiang miscellaneous dialect. Meanwhile, the creation and performance cause of the 'Heart to Heart' art troupe member Dou Shigang in Liumaowan town in Shawan County in Xinjiang had developed vividly. $\mathrm{He}$ was interested in the folk local culture in Xinjiang and familiar with the local dialect, customs and productive life since childhood. Influenced by Xinjiang miscellaneous dialect acting by Zhao Guozhu, he began to create miscellaneous dialect works since 2002, and performed miscellaneous dialect work Boast our Liumaowan Town for the first time in the art performance celebrating ' 3.8 ' in Liumaowan town. Afterwards, he created more than ten excellent miscellaneous dialect works such as Never Dig the Tamarisk, Don't Forget the Communist Party When Rich, Cadre Style Makes Big Change, Xinjiang Dialect, Family Planning, etc. These works were performed in a variety of cultural activities held in Liumaowan town, in Shawan County. Dou Shigang, who was called "king of miscellaneous dialect" in Shawan County, was also invited to participate in a number of promotional activities and opening activities of shopping malls or corporations. The author randomly interviewed 20 people in the process of investigation in the Liumaowan town, among whom 7 people said they could recognize Dou Shigang when meeting him, 16 people had heard his miscellaneous dialect. In recent years, Xinjiang miscellaneous dialect closely follows the development of era. In 2008, Xinjiang miscellaneous dialect became popular once again. Xinjiang TV station launched Xinjiang miscellaneous dialect drama Xinjiang Lamb Skewers, and Mr. Zhao Guozhu also published monograph A Hackle to Folk Miscellaneous dialect. In the same year, the 'Xinjiang mouth' QQ 
expressions created by Wang Xin were particularly prominent. It spread from a QQ expression called 'pear grape melon' since January $7^{\text {th }}, 2008$. Numerous quiet QQ groups were active in using the 'Xinjiang mouth' QQ expressions. Later they were made into series which included 58 relevant QQ expressions. The gratifying thing was that Wang Xin sold 'Xinjiang mouth' QQ expressions to a cultural site, achieving a win-win situation. Afterwards customized ringing tones of mobile phone about Xinjiang miscellaneous dialect such as At the West Bridge, on the Foot of the Red Mountain and Online came in succession. In 2012, with the prevalence of Jiangnan Style, Bachelor Style in the version of Xinjiang miscellaneous dialect appeared and was spread extensively through the internet, micro-letter and other carriers.

Miscellaneous dialect works in whichever period are full of 'burden'. Every word and every joke, though seems absurd and humor, in fact is reasonable and fair. It is close to people, and close to life. In different historical periods, Xinjiang miscellaneous dialect recorded the prevailing politics in society and life of people. It was short and pithy, and suited both refined and popular tastes. It had high entertainment and wide audience. Xinjiang miscellaneous dialect has made a special contribution in enriching people's spiritual life and inheriting national culture.

\section{FUNCTION OF TEACHING IN JOY}

Xinjiang is a multicultural area whose unique culture and regional characteristics gave birth to the unique folk art. Xinjiang miscellaneous dialect is such a characteristic cultural style with distinctive folk customs. Despite basing on Chinese Xinjiang dialect, it widely absorbs minority cultures such as Uygur, Kazak, Hui and so on. Examined from literary language, plots or characters, Xinjiang miscellaneous dialect reveals rich geographical and cultural characteristics. It tells story and heritages culture of Xinjiang, carrying function of enlightening fashion and educating the public.

The society generally uses ethic and law to constraint people's behaviors. In life, however, it is difficult to be found immediately when people's behavior is initially contrary to the morality and law, especially in a society with low productivity and low degree of civilization. Then how did people constraint themselves and advance in such a society? This highlights the educational function of oral folk. The educational function of folk is 'the effect in education and molding the folk takes in the socialization process of individual' ${ }^{[3]}$. Since ancient times, Xinjiang is a sparsely populated area. In the nineteenth century, the productivity in northern Xinjiang where Xinjiang miscellaneous dialect was produced and popular was relatively low. The way people access to information and knowledge was single, coupled with the inconvenient transportation and distant and dangerous road, it was not surprising the phenomenon of 'different customs in two places not far apart' occurred. At that time, the production of Xinjiang miscellaneous dialect was inevitable. According to the author's investigation, there are some common features in early and contemporary miscellaneous dialect artists. They all traveled extensively, rich in experience, familiar with the local and surrounding culture, and had a good memory and the gift of the gab. This laid a foundation for the production of Xinjiang miscellaneous dialect. In a closed environment, Xinjiang miscellaneous dialect had become one of the few forms of entertainment. It was also an effective way for the major audiences (farmers, citizen) to listen to the wonderful story, gain experience and get access to knowledge. Enjoying Xinjiang miscellaneous dialect, they can view an exhibition of good and evil, beauty and ugliness in the world. In this procession, they understood what is right and wrong, forming their own value judgments and moral concepts. This was how the educational function works.

Xinjiang miscellaneous dialect is drawn from the lives of the people, and that is why it can educate. Miscellaneous dialect works, whose plots have extreme similarity with life, are often an enlarged and deformed content of the colorful society. This makes the audiences unconsciously into the storyline when they are enjoying the miscellaneous dialect, making feeling correspond to spirit, unconsciously establishing a link between him and characters in the story. With the evolution of the story, the audience's emotions have accordingly changed. Climax along with undulating valleys, flow through laughter and applause. At the end of the story, the audiences are often led back to reality. The mood swings at that moment, though can not make an immediate change, the unconscious acceptance in this happy atmosphere will affect the audience's mind for a long time. Some familiar miscellaneous dialect scripts is even rooted in the hearts of the people. They can blurt out the plot or make scene reappearance when encountered a similar story plot in life, which plays a role in guidelines or reference. This is the magic effect of edutainment Xinjiang miscellaneous dialect has on people.

Xinjiang miscellaneous dialect has the function of edutainment throughout, with a lot of miscellaneous dialect works proving it. There are miscellaneous dialect works propagandizing ceremony of wedding and funeral such as Marriage Miscellaneous Dialect, Funeral Miscellaneous Dialect (in the beginning of nineteenth century). There are miscellaneous dialect works propagandizing diligence and praying such as Good Weather Good Year (around the year 1931). 
There are miscellaneous dialect works advising people to do good and caring for the elderly such as Talk Household Fairs (around the year 1946), Do Filial Duty to Your Own Mother (after the year 2000). There are works propagandizing steadfast and sincere quality such as Biography of Wang San (around the year 1978). There are works pointing out problems and castigating corruption such as Eating and Drinking Culture must be Prohibited, Cadre Style Makes Big Change (after the year 2000). There are works educating children and persuading young men to cherish time and be on the right path such as Dolls should not be Spoiled, Young People should be on the Right Road, Young People should progress (after the year 2000). There are works protecting the environment such as Never Dig the Tamarisk (after the year 2000). At the end of this work, the author says with allegory: 'Hey! If you eat out the grasses in the wild beach, what will the cattle and sheep?' There are works propagandizing national family planning policy such as One is Good (after the year 2000). The work contains sentences like 'Look at other family raising only one child who is so outstanding. You are always mad with a group of disappointing children. Other family has brought up an excellent child who is elegant enough to show around to the guests and diligent enough to make good cuisines. But the group you have raised even can't stick when made into gelatin and is loose when plugged into the hole of Kang.' The miscellaneous dialect works above are full of profound ideological implication and fairly simple and mundane content. The function of educating and influencing the audiences is visible.

\section{FUNCTION OF HERITAGE IN CULTURAL INTEGRATION}

Xinjiang was originally known as the "western regions". Thus the ancient culture of Xinjiang is known as the Western Regions culture. Xinjiang culture is one of China's cultures rich in regional and national characteristics. Xinjiang is located in central Asia with multi culture. The traditional nomadic culture and oasis agriculture culture, coupled with foreign Buddhist culture, Islamic culture have made Xinjiang culture described as a "Hundred Flowers". Xinjiang miscellaneous dialect is developed on the basis of Han culture, along with heterogeneous and exotic culture factor such as nomadic culture and oasis agriculture culture. From the perspective of formation and development of miscellaneous dialect, the time it was formed and developed included the historical period when a large number of immigrants came to Xinjiang from mainland China and when many people guarded the frontier for the nation. The unique Xinjiang dialect, which was the foundation of the formation and development of Xinjiang miscellaneous dialect, was formed on the basis of dialects fusion of various places. Various ethnic groups of Han in mainland came into Xinjiang along with people and rooted here and merged together, which provided a basic cultural background for the development of Xinjiang miscellaneous dialect.

Cultural of ethnic minorities has exerted a variety of internal and external influence on the formation and development of Xinjiang miscellaneous dialect, which is also a driving force. Examples are that Uyghur story is told in Chinese dialect with novel content and traditional form, which is easy to make people laugh. Hawk and dove by Mr. Zhao Guozhu is a story told in Uyghur Chinese dialect. It gives people a philosophic revelation while amusing them.

As intangible Cultural Heritage, Xinjiang miscellaneous dialect can truly and concretely reflect regional culture characteristics of Xinjiang from all aspects of life because it is simple and easy to understand. There are works publicizing and promoting the culture of Xinjiang such as Xinjiang Dialect (by Zhao Guozhu). This work concisely summarizes Xinjiang dialect by introducing Xinjiang Chinese dialect. It fully embodies rich cultural connotations of folk custom and people's conditions in Xinjiang through words and sentences. Similarly works are Praising Shawan, Let us praise our Liumao town (by Dou Shigang) and so on. There are certainly works eulogizing the party's policies and praising life such as The Village is Making a Difference, Urumqi has Changed a Great Deal (by Zhao Guozhu), Don't Forget the Communist Party When Rich, Don't Forget the Fundamental (by Dou Shigang), etc. These works make directly promotion by comparing the earth-shaking changes in people's living standards, basic necessities and other aspects before and after the reform and opening-up. These works pours out the voice of the people in front of hard cash, singing for the wonderful time today, praising the harmonious and happy life.

\section{ACKNOWLEDGEMENT}

This paper is supported by The National Social Science Fund Project (No: 13CZW092).

\section{REFERENCES}

[1] Local knowledge editorial board, Local Knowledge of Barry Kun kazak Autonomous County, December, 2000.

[2] Dai Mingzhong, Preliminary Study of Xinjiang Miscellaneous Dialect, Tribune of Social Sciences in Xinjiang, the third issue in 1998.

[3] Ouyang Ruoxiu, Theory of Folk Literature, Guangxi Normal University Press, the 1993 edition. 